PII: S0020-7489(96)00009-10

\title{
Continuing pain education in nursing: a literature review
}

\section{ANNEKE L. FRANCKE* \\ BERT GARSSEN \\ HUDA HUIJER ABU-SAAD}

Helen Dowling Institute, Rotterdam. The Netherlands; Department of Nursing Studies, University of Limburg. Maastricht, the Netherlands

\begin{abstract}
Twelve studies on the effects of pain programmes for nurses were reviewed. Most of the programmes focused on aspects of pain, pain medication or pain assessment. Only two programmes (Ferrell et al., 1993, J. Pain Symptom Management, Vol. 8, No. 8, pp. 549-556; Sofaer, 1983, Nurs. Times, Vol. 79, No. 47, pp. 38-42; 1984, Ph.D. Thesis, University of Edinburgh) also paid attention to non-pharmacological nursing interventions. Randomized control groups, established measurement instruments, testing statistics, and long-term follow-up measurements, were not often used in the effect evaluation of the programmes. Effects reported on both nurses and patients were for the most part positive. Given the small number of studies and their methodological limitations, further research into the effectiveness of continuing pain education in nursing is indicated. Copyright (C) 1996 Elsevier Science Ltd.
\end{abstract}

\section{Introduction}

Many nurses feel a need for continuing education (CE) with regard to the subject of pain (Ferrell et al., 1993; Itano and Miller, 1990). This is not without reason. Although prominent international agencies (e.g. WHO, 1986; IASP, 1992) give high priority to pain, basic nursing education devotes limited attention to pain-related topics, and in practice pain is

*Address for correspondence: A. L. Francke, Helen Dowling Institute, Mathenesserlaan 183, 3014 HA Rotterdam, The Netherlands. 
often insufficiently relieved (e.g. Abbott et al., 1990; Carr, 1990; Davis, 1991; Diekmann and Wassem, 1991; Graffam, 1990; Paice et al., 1991).

On account of the great need for $C E$ on pain, research in the effectiveness of pain courses is important. Effect research gives insight into the extent in which the main aim of CE, improving nursing practice and patients' well-being, is achieved. Yet, we were able to find only 15 intervention studies (for the period 1981-June 1995) on the effects of pain courses for nurses. Sources for literature references were Med-Line, Psychlit and Eric databases (CD-ROM), the Journal of Continuing Education in Nursing, the Journal of Nursing Staff Development and a meta-analytic study of Waddell (1990). Because the amount of available literature was modest, strict methodological selection criteria were not employed. Consequently, both controlled and uncontrolled studies were included. However, three of the 15 studies (Dalglish, 1990; Glajchen et al., 1993; Struthers and Jeffrey, 1993) found on the subject were omitted, either because the studies in question were not completed, or because too much relevant information on the programmes, research methods or findings was lacking. The remaining 12 studies are presented (see Tables 1 and 2). Within this scope, the programme characteristics, research methods and findings are discussed. The article closes with some recommendations for the design of future programmes and studies.

\section{Programmes}

\section{Characteristics of programmes}

Among the publications reviewed, most of the programmes paid attention to aspects of pain, e.g. psychological and sociocultural factors which affect pain, pain theories, and pain definitions. Effects and side effects of pain medication and pain assessment were also included in many programmes. As part of the latter, sometimes instruction was given on pain measurement instruments such as pain rating scales or the McGill Pain Questionnaire. The Ferrell et al. (1993) and Sofaer $(1983,1984)$ programmes are the only courses that included non-pharmacological nursing interventions, such as relaxation and distraction.

Various teaching strategies were combined in the programmes: for instance, lectures were often combined with discussions and with practical exercises.

In the majority of the programmes, both participants and educators had a nursing background. In the programme developed by Weissman et al. $(1991,1993)$, which focused on pharmacological pain management, nurses, as well as doctors and pharmacists, participated. In the Sofaer programme $(1983,1984)$, both nurses and nursing assistants participated. According to Sofaer (1984), a programme would be more effective if the whole nursing team participates. In nearly all courses, participants worked in the areas of oncology, orthopedics or surgery. Westfall and Speedie's course (1981) for geriatric nurses was an exception in this respect.

Information is not always given about the duration of the courses. Nonetheless, it appears that the majority of the programmes was of short duration: 8 hours or less. The duration of the 40-hour programme of Ferrell et al. (1993) is exceptional.

\section{Comments on the programmes}

Since pain assessment and pharmacological pain management are often poor in actual practice (e.g. Carr, 1990; Grossman et al., 1991; Lieb Zalon, 1993; Paice et al., 1991), it is good that a relatively high proportion of programmes paid attention to these topics. 
However, although a combination of pharmacological and non-pharmacological methods probably provide the most effective pain relief (McCaffery, 1990a,b), only two programmes (Ferrell et al., 1993; Sofaer, 1983, 1984) also dealt with non-pharmacological nursing interventions.

\section{Research methods}

\section{Characteristics of the research methods}

Several research designs were used to assess programme effectiveness. A design without a control group and with post-measurements only was used in three of the 12 studies reviewed (Degner et al., 1982; McCardle and Van der Wiel, 1993, 1994; Weissman et al., 1991, 1993). This design appears to have been chosen for practical reasons. McCardle and Van der Wiel (1993), for instance, state that they were unable to involve control groups or additional measurements due to limited financial resources.

A design without control group, and with pre- and post-measurements, was most commonly used: in six studies (Davis, 1988; Ferrell et al., 1993; Foglesong, 1983; Foglesong et al., 1987; Myers, 1985; Sofaer, 1983, 1984). Sofaer (1984) states that it is difficult to randomize in a clinical setting, which was for her an important consideration in opting for a design without a control group. Sofaer and the other researchers who chose this design do not discuss the possibility of forming a non-randomized control group.

In two of the studies reviewed (Hauck, 1986; Westfall and Speedie, 1981), a non-randomized control group design with pre- and post-measurements was used. In Westfall and Speedie's study, two nursing homes received a programme and two did not.

The difference in size of the four participating nursing homes was the reason the assignment of the homes to the two conditions was not randomly determined (Westfall and Speedie, 1981).

The 'classic' randomized control group design, in which randomization of individuals takes place, was not used in any of the twelve studies. Randomization of nursing units, however, was used in Camp-Sorrell and O'Sullivan's study (1991): in one hospital two nursing units were randomly allocated to the experimental condition (educational pain programme) and two other nursing units to the control condition (alternative programme).

In addition to randomization, statistical adjustment, restriction and matching (Francke and Duivenvoorden, 1993; Rothman, 1986) may eliminate the effect of confounding variablcs and, consequently, enhance internal validity. The study of Camp-Sorrell and O'Sullivan (1991) is the only one in which statistical adjustment was performed, by a MANCOVA and ANCOVA (Stevens, 1986) in which the baseline score on the variable pain documentation was used as a covariate. In the Foglesong (1983) and Foglesong et al. studies (1987) restriction was applied by selecting patients on the basis of age and postoperative use of pain medication (type of operation was uncontrolled). In Sofaer's study $(1983,1984)$ restriction was applied as well: patients considered suitable for inclusion were those undergoing non-extensive elective major surgery for non-malignant disease. Matching was used only in Westfall and Spccdic's study (1981): the four nursing homes involved were assigned to the conditions on the basis of similarities in characteristics, such as the number of patients admitted and identified medical problems.

Post-measurements were usually within a few days or weeks after the programme. Only in four studies post-measurements were taken after some months or years (Degner et al., 


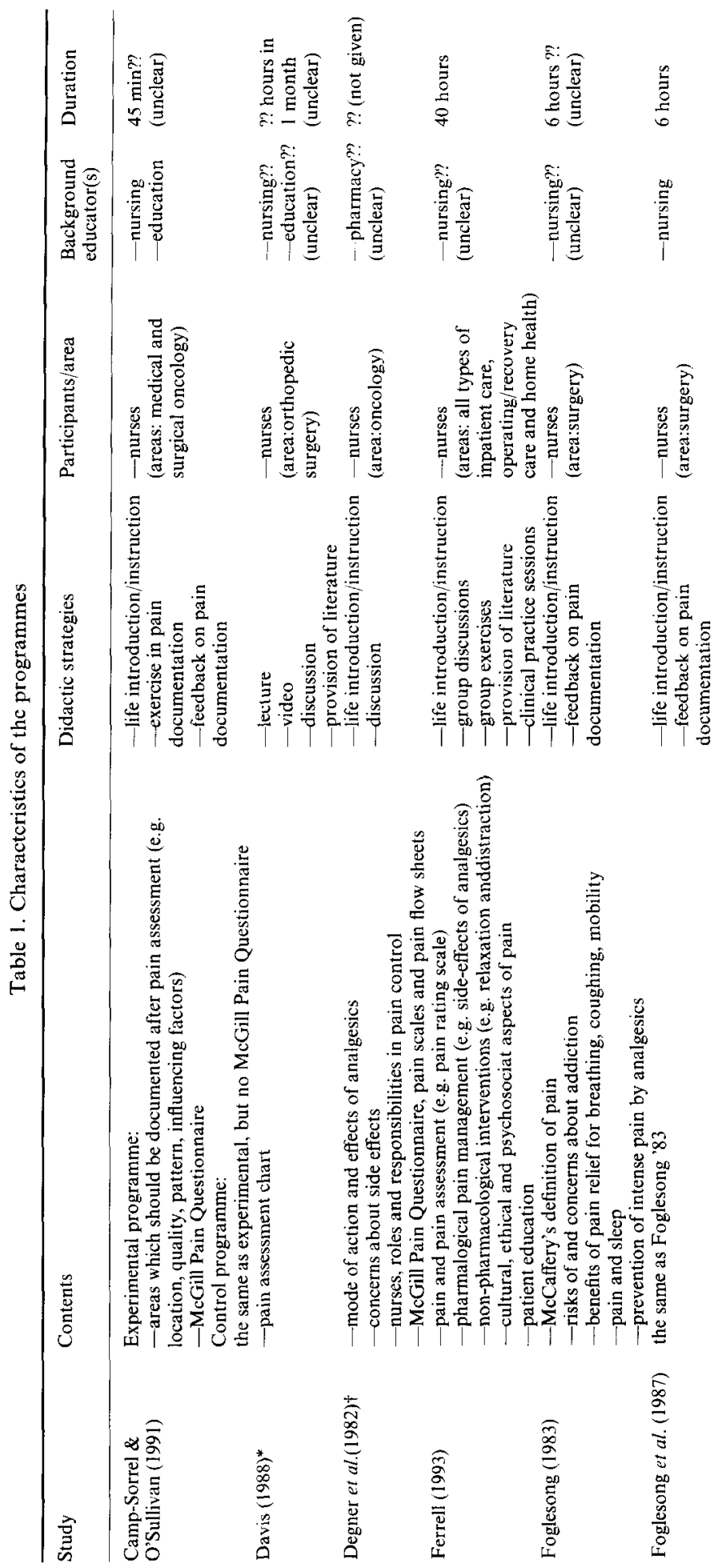




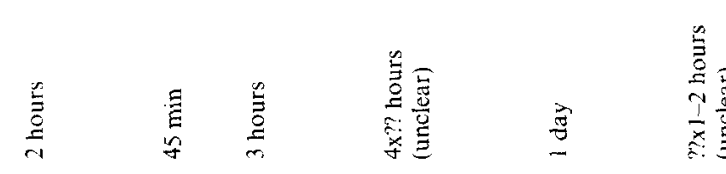

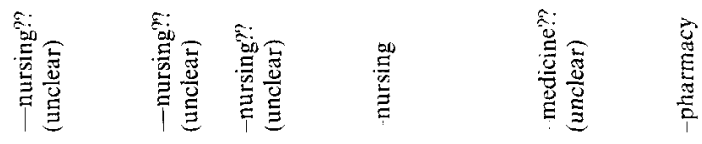

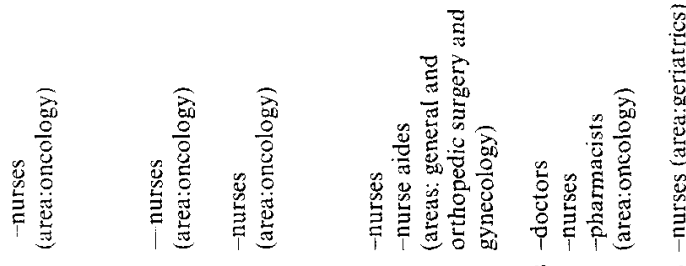

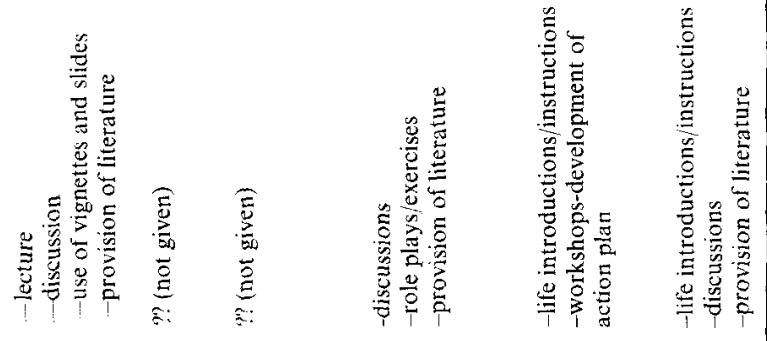

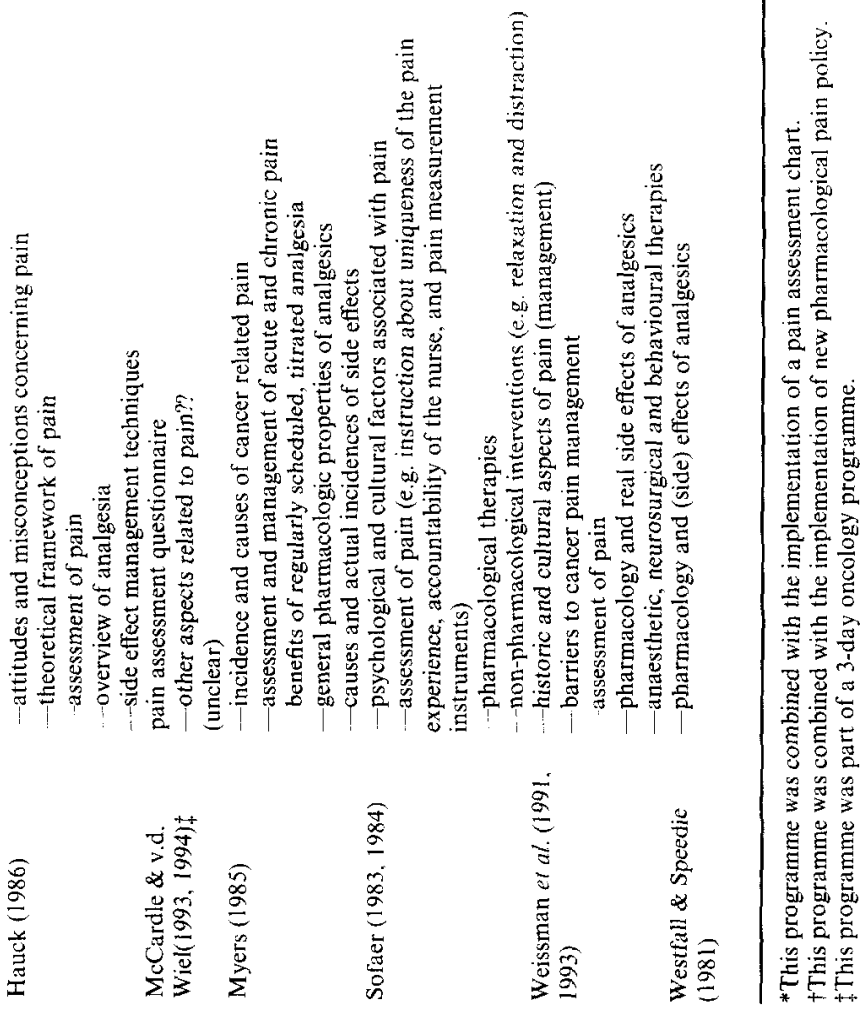




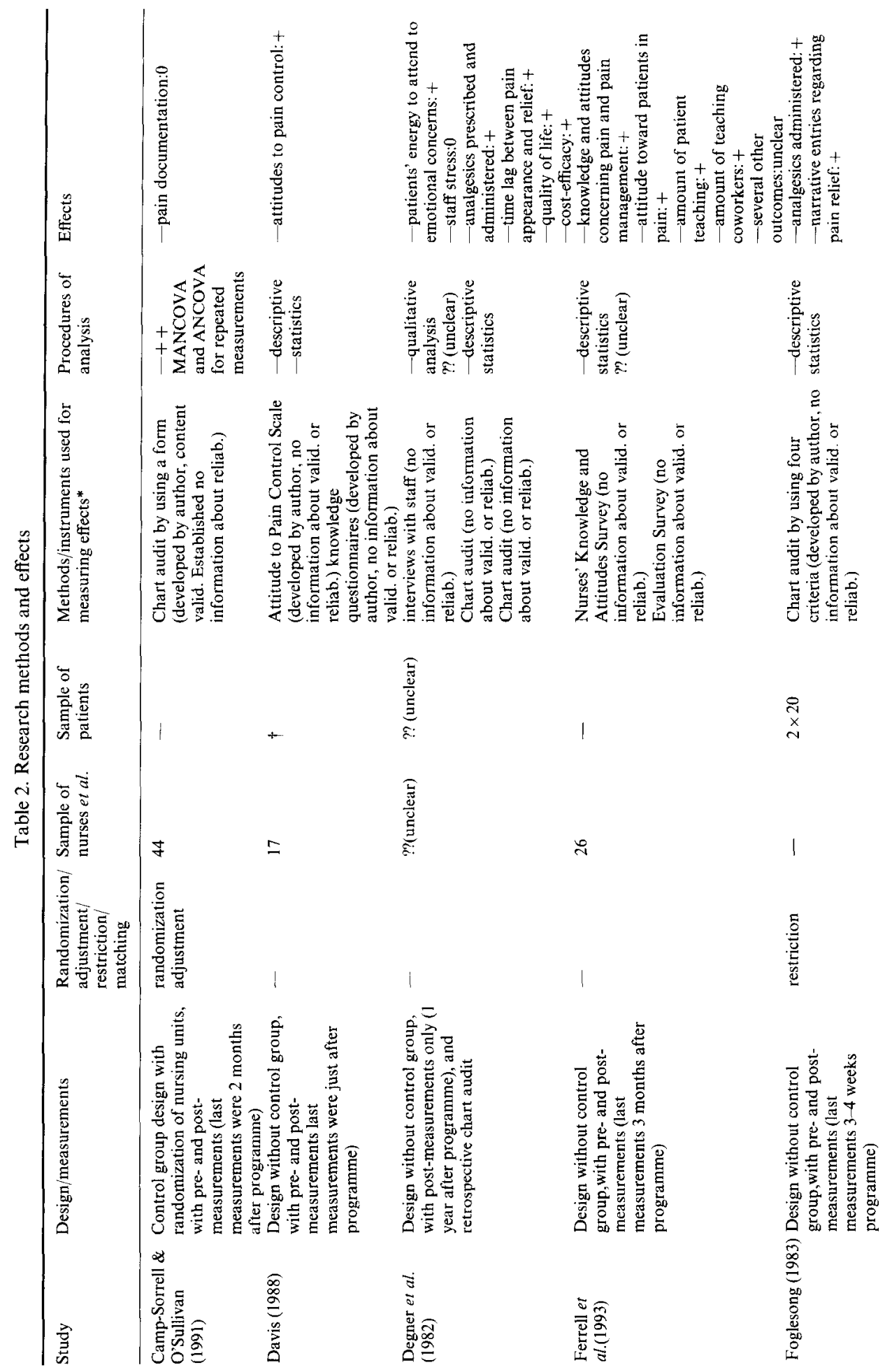



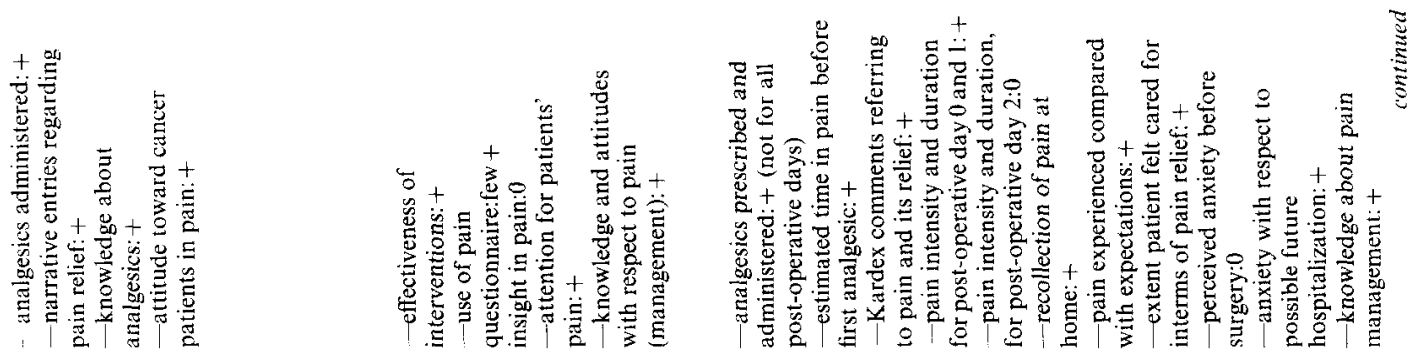

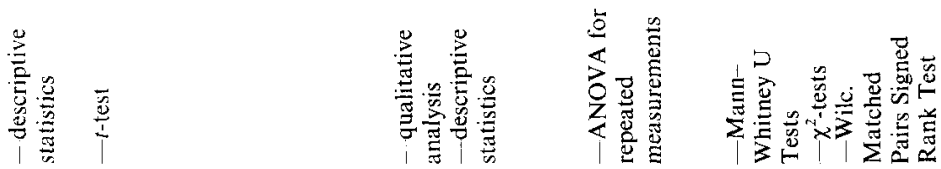

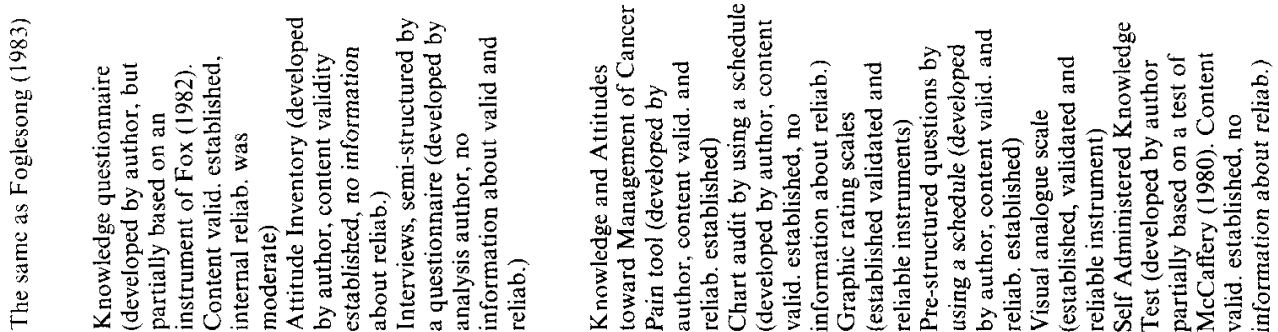

$\underset{n}{x}$

1
n
+
4

in

$\underline{-}$

(6) $\varnothing$

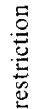

苞

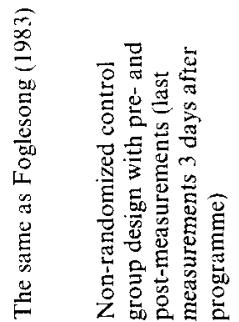

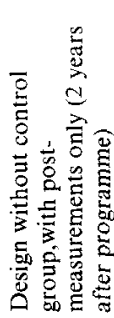

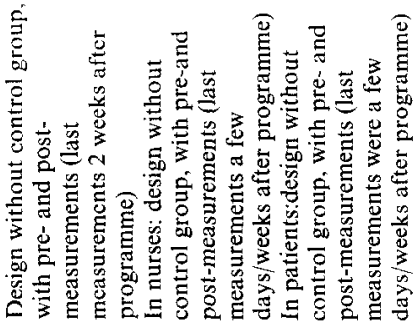

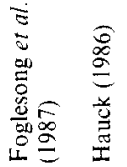

过

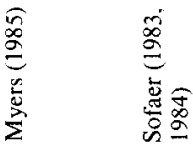




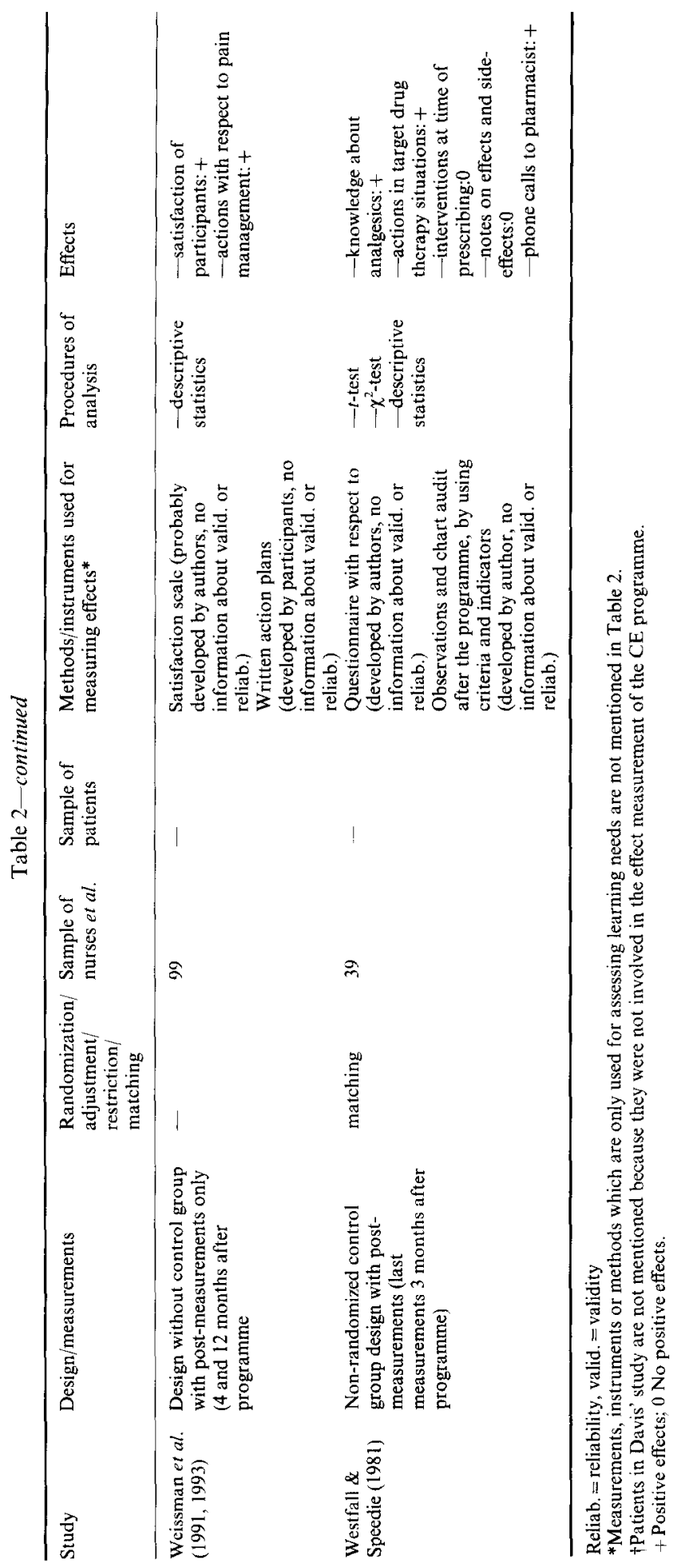


1982; Ferrell et al., 1993; McCardle and Van der Wiel, 1993, 1994; Weissman et al., 1991, 1993).

In 10 of the 12 studies, effects of the programmes were studied in care providers, in most cases nurses only. Sample sizes of care providers varied from 16 (McCardle and Van der Wiel, 1993, 1994) to 99 (Weissman et al., 1991, 1993).

Four studies examined whether the programme had consequences for patients. Degner et al. (1982) did not state the patient sample size, but 40 (Foglesong, 1983) to 98 patients (Sofaer, 1983, 1984) were included in the studies where this information was provided.

Only Sofaer $(1983,1984)$ used established instruments (graphic and visual scales). Other authors employed only self-developed quantitative or qualitative instruments, often based on relevant literature or other instruments. Some authors provide psychometric information on the validity and reliability of the instruments they developed themselves, while others do not.

Not all studies provide clear information about the procedures of analysis followed. However, it appears that most researchers restricted themselves to descriptive statistics in the form of frequencies or percentages. Those who applied testing statistics (Camp-Sorrell and O'Sullivan, 1991; Hauck, 1986; Myers, 1985; Sofaer, 1983, 1984; Westfall and Speedie, 1981 ) used analysis of variance Mann-Whitney U tests and $\chi^{2}$-tests.

\section{Comments on the research methods}

As described above, only few studies (Camp-Sorrell and O'Sullivan, 1991; Hauck, 1986; Westfall and Speedie, 1981) utilized control groups. Uncontrolled studies, however, provide limited insight into the extent to which effects are produced by the programme or by other factors (e.g. organizational changes). When pre-measurements must also be dispensed with (as in three of the 12 studies), drawing valid inferences about effects of a programme becomes precarious.

The Camp-Sorrell and O'Sullivan study (1983) illustrates that randomization of nursing units/wards is an alternative of randomization of individuals. Randomization at unit or ward level may not mean that all experimental subjects will be comparable in all respects to controls. However, it may diminish the chance that all highly motivated subjects will be allocated to the experimental condition, while all less motivated subjects are allocated to the control condition.

Statistical adjustment, restriction and matching may also be valuable procedures for supporting internal validity. In using these procedures, it is important to make a relevant choice in the variables being controlled, for instance on the basis of prior research. Whenever a significant confounding variable is ignored (e.g. when type of operation is uncontrolled, as was the case in the studies of Foglesong and colleagues), statistical adjustment, restriction and matching will be of less value.

In most of the studies the last post-measurements occurred very soon after the programme. Yet, the CE literature indicates that there is a high probability that what has been learned may fade in the course of time (Fielding and Llewelyn, 1987; Oliver, 1984). For this reason, it is unfortunate that in most studies no measurements after a longer period of time have been performed.

Little use of established measurement instruments is a weakness that may be inevitable. Instruments must be well attuned to the programme's content and target group, which is not always the case with established instruments. Yet, for the quality of CE studies and 
their comparability, use of established, valid and reliable instruments is recommended wherever possible. If existent instruments are not useful in their totality, portions can be utilized to develop new instruments, as some authors did. Of course, researchers are accordingly obligated to study and report psychometric qualities.

Often only descriptive statistics were presented. In the context of an effect-oriented study, however, it is advisable to gain insight into the statistical significance of results (this is different for process-oriented or pilot studies). Otherwise, it will remain unclear whether changes should be considered as more than a chance finding. Whenever testing statistics are used, it is important that this be done properly. A few studies require comment in this respect. For instance, in two studies (Hauck, 1986; Westfall and Speedie, 1981) an experimental and a control group were compared by applying two $t$-tests: one for premeasurements and one for post-measurements. An ANOVA procedure would have been more appropriate because there were four groups (two prior and two subsequent to the program). In Myers' study (1985) involving three measurement points, an ANOVA for repeated measurements was performed. However, the preferred method in cases of more than two measurement points is the MAN(C)OVA for repeated measurements (Stevens, 1986). In the other studies where testing statistics were used, the statistical analyses seemed adequate.

In most of the studies reviewed, the sample sizes of nurses and patients (per measurement and per condition) are rather small. However, significant results can be shown in all studies where testing statistics were used, except Camp-Sorrell and O'Sullivan's (1983).

\section{Effects}

\section{Characteristics of the effects}

In 10 of the studies reviewed effects of the programme on nurses were studied (see Table 2). Nearly all authors mention positive effects on nurses' attitudes, knowledge or behaviour related to the assessment and management of pain.

Only Camp-Sorrell and O'Sullivan (1991) do not state a single significant change. They attribute the lack of positive results to factors as the short duration of their programme and the fact that no attention was paid to nursing interventions.

The four studies in which effects of the programme on patient outcomes were assessed, all showed positive results (see Table 2). The studies of Foglesong and colleagues demonstrated that, in comparison with patients nursed before the programme, patients after the programme received more pain medication during the first 24 post-operative hours. Sofaer's study (1983/1984) showed comparable results: patients nursed after the programme received more pain medication, particularly during the first 48 hours after surgery. These patients demonstrated lower pain intensity and shorter pain duration. Degner et al. (1982) assessed an incline in the administration of analgesics after the programme, an increase in the quality of life and pain-free periods. Consequently, patients had more energy to stand up for themselves in interactions with nurses and doctors, which seemed to have resulted in more stress for the staff.

\section{Comments on the effects}

The reporting of a large number of positive findings may be linked to publication bias. Publications are more likely to appear when a programme has proven to have positive 
effects than when few or no effects are found. Such publication bias, the differences in the programmes and the instruments used, methodological limitations and the small number of published studies render impossible a general statement about the effectiveness of pain CE programmes. The limited number of only four published studies concerning effects on patients shows how little is known.

Conclusions about effects are also difficult to make, because the statistical significance of effects shown in some studies (see Table 2) says little about clinical relevance. Slight changes that can be supported statistically may be so negligible as to be of no consequence for nursing practice. However, it can be assumed that studies exhibiting effects in terms of patient results have some clinical relevance. The degree to which effects are clinically relevant, however, is difficult to judge, due to the authors themselves not making any explicit statements about this.

\section{Discussion and recommendations}

Although the 12 studies examined do not constitute conclusive evidence, they do suggest that continuing pain education for nursing staff can have an impact on both nurses and patients. Future methodologically sound studies will have to further examine the effectiveness of different types of pain programmes, varying content, teaching strategies, target group and duration.

Within the scope of future effect studies, it is advisable to use randomized designs, established instruments, longer term follow-up measurements and testing statistics more often. In this way, conclusions on effectiveness may be drawn with more certainty.

Duc to the limited number of studics on effects in patients, it is also advisable to pay special attention to patient outcomes. This would provide more insight into the extent to which the ultimate goal of nursing CE, i.e. promoting patients' health (American Nurses Association, 1986), is achieved.

In future programme development, it is essential to critically evaluate the content of programmes. So far, there has been little or no attention focused on non-pharmacological nursing interventions which are also part of the nursing domain (Herr and Mobily, 1992). Accordingly these interventions certainly ought to be included in some future programmes.

Finally, a lcsson can be distilled from the fact that in previous studies relevant information is often not reported, for instance, information on programme characteristics and procedures of data analysis. A more complete report would give other researchers better opportunities for interpreting effects and for comparing and replicating studies. Journal editors therefore have a responsibility to ensure the completeness of study reports selected for publication.

\section{References}

Abbott, F. V., Gray-Donald, K., Sewitch, M. J., Johnston, C. C., Edgar, L. and Jeans, M. E. (1990). The prevalence of pain in hospitalized patients and resolution over six months. Pain 50, 15-28.

American Nurses Association Council on Continuing Education (1986). Manual for Accreditation as an Approver of Continuing Education in Nursing. American Nurses Association, Kansas City, Missouri.

Camp-Sorrell, D. and O'Sullivan, P. (1991). Effects of continuing education pain assessment and documentation. Cancer Nurs. 14, 49-54.

Carr, E.C. J. (1990). Post-operative pain: patients' expectations and experiences. J. Adv. Nurs. 15, 89-100.

Dalglish, S. (1990). Pain teaching project. Can. Nurse 86, 16. 
Davis, P. S. (1988). Changing nursing practice for more effective control of post-operative pain through a staff initiated educational programme. Nurse Educ. Today 8, 325-331.

Davis, P. S. (1991). Teaching nurses about managing pain. Nurs. Standard 5(52), 30-33.

Degner, L. F., Fujii, S. H. and Levitt, M. (1982). Implementing a program to control chronic pain of malignant disease for patients in an extended care facility. Cancer Nurs. 5(August), 263-268.

Diekmann, J. M. and Wassem, R. A. (1991). A survey of nursing students' knowledge of cancer pain control. Cancer Nurs. 14(6), 314-319.

Fielding, R. G. and Llewelyn, S. P. (1987). Communication training in nursing may damage your health and enthusiasm: some warnings. J. Adv. Nurs. 12, 281-290.

Foglesong, D. H. (1983). The impact of a staff development offering on nursing practice. J. Contin. Educ. Nurs. $14(6), 12-15$.

Foglesong, D. H., Lambert, J. and Emerick, J. (1987). Variables which influence the effect of staff development on nursing practice. J. Contin. Educ. Nurs. 18, 168-171.

Ferrell, B. R., Grant, M., Ritchey, K. J., Ropchan, R. and Rivera, L. M. (1993). The pain resource nurse training program: a unique approach to pain management. J. Pain Symptom Management 8(8), 549-556.

Francke, A. L. and Duivenvoorden, H. J. (1993). Methodologie van Interventie-onderzoek. In Verplegen. Interveniëren en Evalueren. Verpleegkundig Interventie-onderzoek in de Praktiik (Francke, A.L., Ed.), pp. 13-25. Swets en Zeitlinger, I isse

Glajchen, M., Blum, D. and Calder, K. (1993). Training health care professionals in cancer pain: translating research into practice. In Proceedings of the Psycho-oncology Congress V: Psychosocial Factors in Cancer Risk and Survival, October 1993, New York.

Graffam, S. (1990). Pain content in the curriculum: a survey. Nurse Educ. 15, 20-23.

Grossman, S. A., Scheidler, V. R., Swedeen, K., Mucenski, J. and Piantadosi, S. (1991). Correlation of patient and caregiver ratings of cancer pain. J. Pain Symptom Management 6(2), 53-57.

Hauck, S. (1986). Pain: problem for the person with cancer. Cancer Nurs. 9(2), 66-76.

Herr, K. A. and Mobily, P. R. (1992). Interventions related to pain. Nurs. Clin. N. Am. 27(2), 347-368.

International Association for the Study of Pain (1992). Management of Acute Pain. A Practical Guide. IASP Publications, Seattle.

Itano, J. and Miller, C. A. (1990). Learning needs of Oncology Nursing Society members. Oncol. Nurs. Forum 17(5), 697-703.

Lieb Zalon, M. (1993). Nurses' assessment of postoperative patients' pain. Pain 54, 329-334.

McCaffery, M. (1980). Understanding your patient's pain. Nursing 80(September), 26-31.

McCaffery, M. (1990). Nursing approaches to nonpharmacological pain control. Int. J. Nurs. Stud. 27(1), 1-5.

McCardle, M. and Van der Wiel, Y. (1993). Ervaringen van wijkverpleegkundigen met het afnemen van de pijnanamnese bij patiënten met kanker in de thuissituatie. Unpublished report. Hogeschool Nijmegen en Integraal Kankercentrum Oost, Nijmegen.

McCardle, M. and Van der Wiel, Y. (1994). Gescoord heb ik nog nooit! Ervaringen van wijkverpleegkundigen met het afnemen van de pijnanamnese. MGZ, Thuiszorg en Preventie 22(1), 36-39.

Myers, J. (1985). Cancer pain: assessment of nurses' knowledge and attitudes. Oncol. Nurs. Forum 12(4), 62-66.

Paice, J. A., Mahon, S. M. and Faut-Callahan, M. (1991). Factors associated with adequate pain control in hospitalized post-surgical patients diagnosed with cancer. Cancer Nurs. 14(6), 298-305.

Rothman, K. J. (1986). Modern Epidemiology. Little, Brown and Company, Boston, Mass.

Sofaer, B. (1983). Pain relief-the core of nursing practicc. Nurs. Times 79(47), 38-42.

Sofaer, B. (1984). The effect of focused education for nursing teams on post-operative pain of patients. Unpublished $\mathrm{PhD}$ thesis. University of Edinburgh, Edinburgh.

Stevens, J. (1986). Applied Multivariate Statistics for the Social Scientists. Lawrence Erlbaum, Hillsdale, NJ.

Struthers, C. L. and Jeffrey, J. (1993). Nurses' knowledge and assessment of post-operative pain before and after a continuing education session. In Proceedings of the 7th World Congress on Pain, pp. 397, August 1993. IASP, Paris.

Waddell, D. L. (1990). The effects of continuing education on nursing practice: a meta-analysis. Unpublished $\mathrm{PhD}$ thesis. University of Georgia, Georgia.

Weissman, D. E., Gutmann, M. and Dahl, J. L. (1991). Physician cancer pain education: a report from the Wisconsin Cancer Pain Initiative. J. Pain Symptom Management 6(7), 445-448.

Weissman, D. E., Dahl, J. L. and Beasly, J. W. (1993). The Cancer Pain Role Model Program of the Wisconsin Cancer Pain Initiative. J. Pain Symptom Management 8(1), 2935.

Westfall, L. K. and Speedie, S. M. (1981). The effects of inservice education provided by consultant pharmacists on the behavior of nurses in long-term care facilities. Drug Intell. Clin. Pharm. 15(October), 777-781. 